\title{
Synthetic seed production from encapsulated somatic embryos of cork oak (Quercus suber L.) and automated growth monitoring
}

\author{
B. Pintos • M. A. Bueno • B. Cuenca • \\ J. A. Manzanera
}

\begin{abstract}
Cork oak (Quercus suber) somatic embryos were coated with alginate for the production of synthetic seeds and their storability for commercialization was investigated. Also, the automatic monitoring of somatic embryo growth with a digital system of image capture was tested. A power regression model was fitted between size and fresh weight (Adjusted R-squared - 0.96). This method permitted growth assessment without contamination risk and opens the possibility of an automated control of culture growth for the future up scaling of plant production. Conversion rate of synthetic seeds was higher on medium supplemented with mineral nutrients than on medium without nutrients. Also, when the somatic embryos were coated without mineral nutrients added to the capsule, conversion rate was significantly lower. The addition of sucrose to the capsule had no significant effect on the conversion rate. No differences were recorded between 50 and $100 \mathrm{mM}$ $\mathrm{CaCl} 2$ for capsule complexation. Synthetic seeds were cold stored at $4^{\circ} \mathrm{C}$ for two months without significant
\end{abstract}

loss of conversion capacity. The present study reports the first attempts to determine optimal storage time and conditions for conversion of encapsulated somatic embryos of cork oak.

Keywords Automated monitoring • Cork oak • Encapsulation - Quercus suber L. • Seed storage $\cdot$ Synthetic seeds
Abbreviations
BA Benzylaminopurine
2,4-D 2,4-Dichlorophenoxy acetic acid
IB A Indole-3-butyric acid
MS Murashige and Skoog's medium (1962)

\section{Introduction}

Cork oak (Quercus suber L.), an emblematic Mediterranean forest tree species of both ecologic and economic value for the cork and agroforestry enterprises, has several difficulties for the sustainable management of its populations. These are the age of sexual maturity and irregular reproductive cycle, the difficulty of seed conservation and the difficulty of vegetative reproduction, which are serious drawbacks for the deployment of the classical genetic improvement programs in this species. Somatic embryogenesis has been used as a good alternative to the propagation of selected trees (Bueno et al. 1992; Manzanera et al. 
1993). A bottle-neck of somatic embryogenesis is the late maturation, acclimation and establishment phase. Maturation has been hampered in many woody species by precocious conversion, spontaneous repetitive embryogenesis, embryo dormancy, and immaturity problems. Osmotic treatments have been used to promote somatic embryo conversion of cork oak (Garcia-Martin et al. 2001,2005) and of several related species, such as $Q$. robur (Chalupa 1990), and $Q$. ilex (Mauri and Manzanera 2003, 2004). Nevertheless, little attention has been devoted to late maturation and conversion. During maturation, cell expansion and storage substance accumulation take place, which is crucial for fuelling the conversion process. Embryo weight increment is an indicator of embryo quality and a pre-requisite for successful conversion (GarciaMartin et al. 2005).

A well-tuned somatic embryogenesis system is also required for synthetic seed production. Synthetic, artificial or somatic seeds are analogous to the true or botanical seed, and consist of a somatic embryo surrounded by one or more artificial layers forming a capsule (Cangahuala-Inocente et al. 2007). Synthetic seeds may provide the only technology realistically amenable to the extensive scale-up required for the commercial production of some clones (Bornman 1993). Synthetic seeds have multiples advantages, including easy handling and transportation, potential long-term storage, higher scale-up capacity, uniformity in production, potential for automation of the whole production process, seeding of clonal varieties, and may provide a means for maintenance of elite germplasm (Singh et al. 2007). High conversion ability and compact size are indispensable features for synthetic seeds (Nieves et al. 1995).

Studies on synthetic seed production using somatic embryos have been reported in a few forest species, such as Paulownia elongata (Ipekci and Gozukirmizi 2003), Eucalyptus citriodora (Muralidharan and Mascarenhas 1995) and Chamaecyparis pisifera (Maruyama et al. 2003). Somatic embryos of Quercus serrata $\mathrm{L}$. were encapsulated in $4 \%$ sodium alginate with half-strength MS medium (Murashige and Skoog 1962) and 6-benzylaminopurine (BA), but only root elongation was observed upon conversion (Ishii et al. 1999). Synthetic Quercus robur L. seeds were produced by embedding somatic embryos in various sodium alginate concentrations. Four percent sodium alginate was found to be more appropriate than concentrations of 6.8 or $3 \%$ (Wilhelm et al. 1999). The alginate matrix around the somatic embryos provides resistance to manipulation and transport, and preserves viability and conversion, especially if the encapsulated matrix is enriched by nutritive substances (synthetic endosperm) (Prewein and Wilhelm 2003).

In Arnebia euchroma (Royle) Jonst., the encapsulated embryos showed a significantly lower conversion percentage than non-encapsulated embryos set to convert either on full strength or on half-strength MS medium supplemented with $2.5 \mathrm{uM}$ indole-3-butyric acid (IBA) and 2.5 uM BA (Manjkhola et al. 2005). Encapsulation of proembryogenic masses or somatic embryos derived from suspension cells provided successful conversion rate in Spartina alterniflora (Utomo et al. 2008). Lower conversion percentages of encapsulated somatic embryos in comparison to nonencapsulated somatic embryos is in conformity with the findings of several researchers (Bapat and Rao 1988; Ghosh and Sen 1994).

Storage of somatic embryos or vegetative propagules using an alginate-encapsulation protocol has been attempted in only a few species with various degrees of success, but would be very useful for cryopreservation of encapsulated germplasm of woody species, such as oaks (Gonzalez-Benito et al. 1999), Punica granatum (Naik and Chand 2006) and Vitis sp. (Wang et al. 2004).

The objectives of this paper are to develop an efficient method for plantlet regeneration of cork oak from synthetic seeds produced from somatic embryos, and to test the automatic monitoring of somatic embryo growth and eventual maturation in vitro, for the standardization of synthetic seed production.

\section{Material and methods}

\section{Plant material}

Immature acorns were collected every week, from selected trees of Quercus suber L., located in Extremadura (Western Spain), during the period of fruit development, from July to October. Cupules were peeled from immature acorns and these were surface-sterilized by immersion in $70 \%$ (v/v) ethanol for $30 \mathrm{~s}$ and in $2 \%(\mathrm{v} / \mathrm{v})$ sodium hypochlorite $(3.5 \%$ (w/v) active chlorine) with a drop of 'Tween 20 ' for 
20 min followed by three rinses in sterile distilled water over $10 \mathrm{~min}$ each. Immature zygotic embryos were isolated, dissected and cultured under aseptic conditions.

\section{Culture media}

Basal culture medium for somatic embryos contained full macronutrients (Sommer et al. 1975), microminerals and cofactors (Murashige and Skoog 1962), $3 \%(\mathrm{w} / \mathrm{v})$ sucrose and was solidified with $0.8 \%(\mathrm{w} / \mathrm{v})$ agar (Panreac ${ }^{\circledR}$, Registry of the Chemical Abstracts Service (CAS code) 9002-18-0, from Panreac Quimica S.A., Spain; Bueno et al. 1992). All media were adjusted to $\mathrm{pH}=5.6$ after addition of agar and before autoclaving at $101.3 \mathrm{kPa}\left(120^{\circ} \mathrm{C}\right)$ for $20 \mathrm{~min}$. In all experiments, plant growth regulators, amino acids and activated charcoal are added to the medium before autoclaving.

Somatic embryo induction from zygotic embryos

Cork oak immature zygotic embryos were cultured in $9 \mathrm{~cm}$ diameter Petri dishes containing $25 \mathrm{ml}$ basal medium supplemented with 2.3 uM 2,4-dichlorophenoxyacetic acid $(2,4-\mathrm{D})$ for one month. One embryo was cultured per Petri dish, and these were sealed with Parafilm ${ }^{\circledR}$. Then embryos were transferred to basal medium supplemented with $3.4 \mathrm{mM}$ glutamine (Gin) without 2,4-D for somatic embryo induction. The cultures were maintained in a growth chamber at $25 \pm 2{ }^{\circ} \mathrm{C}$ under cool-white fluorescent light (50 umol m s photon flux density) and a $16 \mathrm{~h}$ photoperiod.

\section{Somatic embryo maturation}

Somatic embryos at the cotyledonary stage, 3 to $4 \mathrm{~mm}$ in size and of translucent appearance, were matured in $9 \mathrm{~cm}$ diameter Petri dishes containing $25 \mathrm{ml}$ basal culture medium supplemented with $1 \%$ activated charcoal. The cultures were kept in darkness for one month at $25^{\circ} \mathrm{C}$, with four embryos per Petri dish. Then, mature embryos were stratified at $4^{\circ} \mathrm{C}$ for eight weeks in darkness, in Petri dishes containing full macronutrients (Sommer et al. 1975), microminerals and cofactors (Murashige and Skoog 1962), 3\% (w/v) sucrose, $0.8 \%(\mathrm{w} / \mathrm{v})$ agar and supplemented with $1 \%$ activated charcoal. Then, they were re-hydrated individually in $15 \mathrm{~cm}$-long and $2.5 \mathrm{~cm}$ diameter test tubes containing $10 \mathrm{ml}$ distilled sterile water and plugged with BellCo ${ }^{\circledR}$ caps, for $24 \mathrm{~h}$ at $4{ }^{\circ} \mathrm{C}$ in darkness prior to encapsulation and conversion.

Automatic monitoring of somatic embryo growth

For automated sizing of embryos, the projected area of each embryo was measured with an image analyzer (Image Tool ${ }^{\circledR}$ ). We define projected area of any object (i.e., embryo) as the area delimited by the rectilinear projection of the outline of a surface of any shape onto the plane perpendicular to the projection. Each embryo was set in a Petri dish with $0.8 \%(\mathrm{w} / \mathrm{v})$ agar, and the contrast of the digital camera was set to sharply differentiate the opaque somatic embryo from the surrounding transparent medium. The digital camera was focused in perpendicular direction to the table plane and recorded the embryo projected area. Also, each embryo for which the projected area was measured was put into a previously tared sterile Petri dish and was weighed in aseptic conditions. One month later, both projected area and fresh weight were measured again in the mature somatic embryos and linear or non-linear regression models fitted between both variables with the statistical package SPSS 14.0.1 for Windows (SPSS, 2005). A total of 1,440 cork oak somatic embryos were measured. For this experiment, nine regression models were tested: linear, logarithmic, inverse, compound, power, quadratic, cubic, exponential and sigmoid. The R-squared statistic was calculated for each model and the one with the best fit was selected.

\section{Encapsulation of mature somatic embryos}

Mature somatic embryos $(1.5 \pm 0.5 \mathrm{~cm}$-size $)$ were encapsulated by immersion in a solution which contained full macronutrients (Sommer et al. 1975), except for $\mathrm{CaCl} 2$ which was excluded from the solution, microminerals and cofactors (Murashige and Skoog 1962), and supplemented with 5\% (w/v) sodium alginate (alginic acid Sodium salt from brown algae, Fluka ${ }^{\circledR}$, CAS-code 9005-38-3). This is called encapsulation medium. Then these embryos are immersed in a vial containing $50 \mathrm{mM} \mathrm{CaCl} 2$ for $20 \mathrm{~min}$ for complexing. In some experiments, $\mathrm{CaCl} 2$ concentration was doubled to $100 \mathrm{mM}$. 
Experiment 1: effect of encapsulation combined with the mineral composition of the conversion medium on cork oak synthetic seed conversion

Mature somatic embryos were subjected to the following two-way experimental design: either encapsulated with $5 \%(\mathrm{w} / \mathrm{v})$ sodium alginate without mineral nutrients and subsequently immersed in $50 \mathrm{mM} \mathrm{CaCl} 2$ for $20 \mathrm{~min}$, or non-encapsulated for those embryos used as controls, and both types were set to convert either on conversion medium, consisting of macronutrients (Sommer et al. 1975), microminerals and cofactors (Murashige and Skoog 1962), $1.5 \%(\mathrm{w} / \mathrm{v})$ sucrose, $1 \%(\mathrm{w} / \mathrm{v})$ agar, $0.2 \mathrm{uM}$ BA and $0.5 \mathrm{uM} \mathrm{IB} \mathrm{A,} \mathrm{or} \mathrm{on} 0.8 \%(\mathrm{w} / \mathrm{v})$ agar medium without mineral nutrients, cofactors or plant growth regulators. Forty embryos were converted per treatment (160 embryos for the whole experiment).

Experiment 2: effect of the addition of sucrose and mineral nutrients to the capsule on cork oak synthetic seed conversion

In this experiment, mature somatic embryos were re-hydrated individually in test tubes containing $10 \mathrm{ml}$ distilled sterile water for $24 \mathrm{~h}$ at $4^{\circ} \mathrm{C}$ in darkness prior to encapsulation. The effect of the addition of mineral nutrients and sucrose to the capsule of cork oak synthetic seeds on later conversion was tested in a factorial design with the following treatments: encapsulation medium consisting of $5 \%(\mathrm{w} / \mathrm{v})$ sodium alginate without mineral nutrients and without sucrose (control), 5\% (w/v) sodium alginate and $1.5 \%(\mathrm{w} / \mathrm{v})$ sucrose without mineral nutrients, basal encapsulation medium supplemented with full macronutrients (Sommer et al. 1975), except for $\mathrm{CaCl} 2$ which was excluded from the solution, microminerals and cofactors (Murashige and Skoog 1962), 5\% (w/v) sodium alginate and without sucrose, and basal encapsulation medium, supplemented with full macronutrients (Sommer et al. 1975), except for $\mathrm{CaCl} 2$ which was excluded from the solution, microminerals and cofactors $(\mathrm{Mu}-$ rashige and Skoog 1962), 5\% (w/v) sodium alginate and $1.5 \%(\mathrm{w} / \mathrm{v})$ sucrose. In all treatments, the encapsulation medium was supplemented with $0.2 \mathrm{uM} \mathrm{BA}$ and $0.5 \mathrm{uM}$ IBA and complexed with $50 \mathrm{mM} \mathrm{CaCl}_{2}$ for $20 \mathrm{~min}$. Then, all treatments were set to convert in Petri dishes with $0.8 \%(\mathrm{w} / \mathrm{v})$ agar without any further additives. Forty three embryos were used per treatment (172 embryos for the whole experiment).

Experiment 3: effect of the addition of sucrose to the capsule and cold storage of synthetic seeds on the conversion rate

Mature somatic embryos were encapsulated with encapsulation medium, consisting of full macronutrients (Sommer et al. 1975), except for $\mathrm{CaCl} 2$ which was excluded from the solution, microminerals and cofactors (Murashige and Skoog 1962), either supplemented with $3 \%(\mathrm{w} / \mathrm{v})$ sucrose or not, and the alginate capsule was complexed with $100 \mathrm{mM} \mathrm{CaCl} 2$ for $20 \mathrm{~min}$, except for those embryos used as controls, which were not encapsulated. Those embryos subjected to encapsulation were either set to convert on basal medium supplemented with $1 \%(\mathrm{w} / \mathrm{v})$ agar, $1.5 \%$ (w/v) sucrose, $0.2 \mathrm{uM} \mathrm{BA}$ and $0.5 \mathrm{uM}$ IBA, or cold stored at $4^{\circ} \mathrm{C}$ inside test tubes containing $1 \mathrm{ml}$ sterile distilled water, for two or five months, prior to conversion on basal medium supplemented with $1 \%$ $(\mathrm{w} / \mathrm{v})$ agar, $1.5 \%(\mathrm{w} / \mathrm{v})$ sucrose, $0.2 \mathrm{uM}$ BA and $0.5 \mathrm{uM}$ IBA. Thus, a two-way experiment was designed by combination of the effect due to the addition of sucrose to the capsule, and the effect due to the cold storage of cork oak synthetic seeds. Thirty embryos were used per treatment when embryos were encapsulated with the addition of $3 \%(\mathrm{w} / \mathrm{v})$ sucrose, and ten embryos per treatment when they were encapsulated without sucrose. Thus a total of 160 embryos were used for the whole experiment.

Experiment 4: effect of encapsulation, cold storage at $4^{\circ} \mathrm{C}$ and calcium chloride concentration on the conversion of encapsulated somatic embryos

Mature somatic embryos were immersed in basal encapsulation medium, consisting of full macronutrients (Sommer et al. 1975), except for $\mathrm{CaCl} 2$ which was excluded from the solution, microminerals and cofactors (Murashige and Skoog 1962) and supplemented with $5 \%(\mathrm{w} / \mathrm{v})$ sodium alginate, except for those embryos used as controls. The basal encapsulation medium was complexed for 20 min with $\mathrm{CaCl}_{2}$, either at 50 or $100 \mathrm{mM}$ concentrations. With each of both concentrations, the following treatments were tested: encapsulation with basal encapsulation medium and subsequent cold storage at $4{ }^{\circ} \mathrm{C}$ for two months (20 
embryos treated with $50 \mathrm{mM} \mathrm{CaCl}$ and 10 with $100 \mathrm{mM}$ ), encapsulation with basal encapsulation medium without later cold storage (30 embryos treated with $50 \mathrm{mM} \mathrm{CaCl} l_{2}$ and 10 with $100 \mathrm{mM}$ ), and the controls (no encapsulation, no cold storage; 30 embryos treated with $50 \mathrm{mM} \mathrm{CaCl}_{2}$ and 10 with $100 \mathrm{mM}$ ). A total of 110 embryos were used for the whole experiment.

\section{Conversion medium}

After stratification and eventual encapsulation procedures, mature $1.5 \pm 0.5 \mathrm{~cm}$-sized synthetic seeds, or somatic embryos in the case of controls, were converted to plantlets in test tubes with basal medium supplemented with $1 \%(\mathrm{w} / \mathrm{v})$ agar, $1.5 \%(\mathrm{w} / \mathrm{v})$ sucrose, $0.2 \mathrm{uM} \mathrm{BA}$ and $0.5 \mathrm{uM} \mathrm{IBA}$, and plugged with BellCo® caps, unless otherwise stated. Conversion took place in a growth chamber at $25 \pm 2{ }^{\circ} \mathrm{C}$ under coolwhite fluorescent light (50 umol m $\mathrm{m}^{-2} \mathrm{~s}^{-1}$ photon flux density) and a $16 \mathrm{~h}$ photoperiod. Conversion rate was assessed 30 days after the beginning of the experiment.

\section{Statistics}

For statistical calculations of the conversion (i.e., elongation of both embryo root and shoot) rate of the different experiments, expressed as percentages, a log-linear model was fitted using a Chi-square test at the level of $\mathrm{a}=0.05$ significance, with the General log-linear analysis module of the statistical package SPSS v 14.0.1 for Windows (SPSS inc., 2005).

\section{Results}

Automatic monitoring of somatic embryo growth

Determination coefficients for the regression models fitted between projected area and fresh weight are shown in Table 1 . The best fitting model is the power regression (Adjusted R-squared $=0.96447$, $P<0.0001): \quad \mathrm{FW}=0.607272 \times \mathrm{PA}^{1224703}$ Where FW is the somatic embryo fresh weight, in $\mathrm{mg}$, and PA the projected area, in $\mathrm{mm}^{2}$ (Fig. 1).

Encapsulation of mature somatic embryos

The cotyledons of the encapsulated mature somatic embryos turned green within a week of the beginning
Table 1 Multiple correlation coefficient (Multiple R), R-squared, Adjusted determination coefficient (Adjusted R-squared) and significance probability $(P)$ for the regression models fitted between fresh weight of cork oak somatic embryos and their projected area, which is the area delimited by the rectilinear projection of the outline of the embryo shape onto a plane perpendicular to the optical axis of the recording digital camera

\begin{tabular}{lllll}
\hline $\begin{array}{l}\text { Regression } \\
\text { model }\end{array}$ & Multiple R & R-squared & $\begin{array}{l}\text { Adjusted } \\
\text { R-squared }\end{array}$ & $P$ \\
\hline Linear & 0.90684 & 0.82235 & 0.82085 & 0.0001 \\
Logarithmic & 0.89031 & 0.79265 & 0.79089 & 0.0001 \\
Inverse & 0.68086 & 0.46357 & 0.45902 & 0.0001 \\
Quadratic & 0.93717 & 0.87828 & 0.87620 & 0.0001 \\
Cubic & 0.93719 & 0.87832 & 0.87518 & 0.0001 \\
Compound & 0.85379 & 0.72895 & 0.72666 & 0.0001 \\
Power & 0.98222 & 0.96476 & 0.96447 & 0.0001 \\
Sigmoid & 0.87701 & 0.76914 & 0.76719 & 0.0001 \\
Exponential & 0.85379 & 0.72895 & 0.72666 & 0.0001 \\
\hline
\end{tabular}

of the conversion experiments. Embryos converted to plantlets formed a well developed root which emerged through the alginate capsule. In most cases, cork oak plantlet regeneration was complete within a month (Fig. 2).

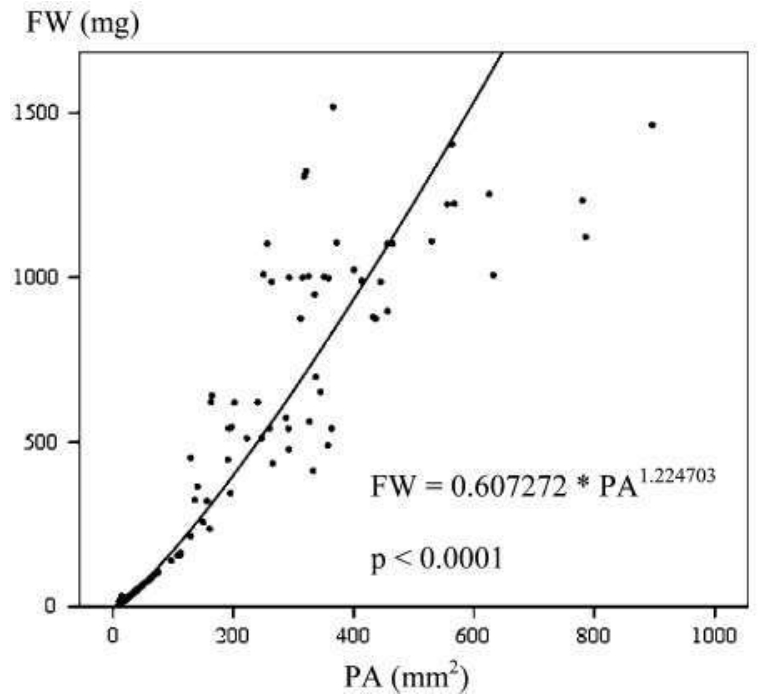

Fig. 1 Power regression model fitted between projected area $\left(\mathrm{PA}\right.$, in $\mathrm{mm}^{2}$ ) and fresh weight $(\mathrm{FW}$, in $\mathrm{mg}$ ) of cork oak somatic embryos cultured in basal medium with $1 \%$ activated charcoal: $\mathrm{FW}=0.607272 * \mathrm{PA}^{1224703}(P<0.0001)$ 
Fig. 2 (a) Cork oak mature somatic embryo,

(b) Synthetic seed encapsulated with $5 \%(\mathrm{w} / \mathrm{v})$ sodium alginate and complexed with $50 \mathrm{mM}$ $\mathrm{CaCl}_{2}$ for $20 \mathrm{~min}$, containing a mature somatic embryo, (c) Encapsulated somatic embryo re-hydrated individually in a test tube containing $10 \mathrm{ml}$ distilled sterile water for $24 \mathrm{~h}$ at $4{ }^{\circ} \mathrm{C}$ in darkness prior to conversion, (d) Emergence of the shoot from a germinating cork oak synthetic seed,

(e) Converted cork oak plantlet from a synthetic seed, (f) Cork oak plantlet converted on agar medium from an encapsulated somatic embryo after one month from sowing
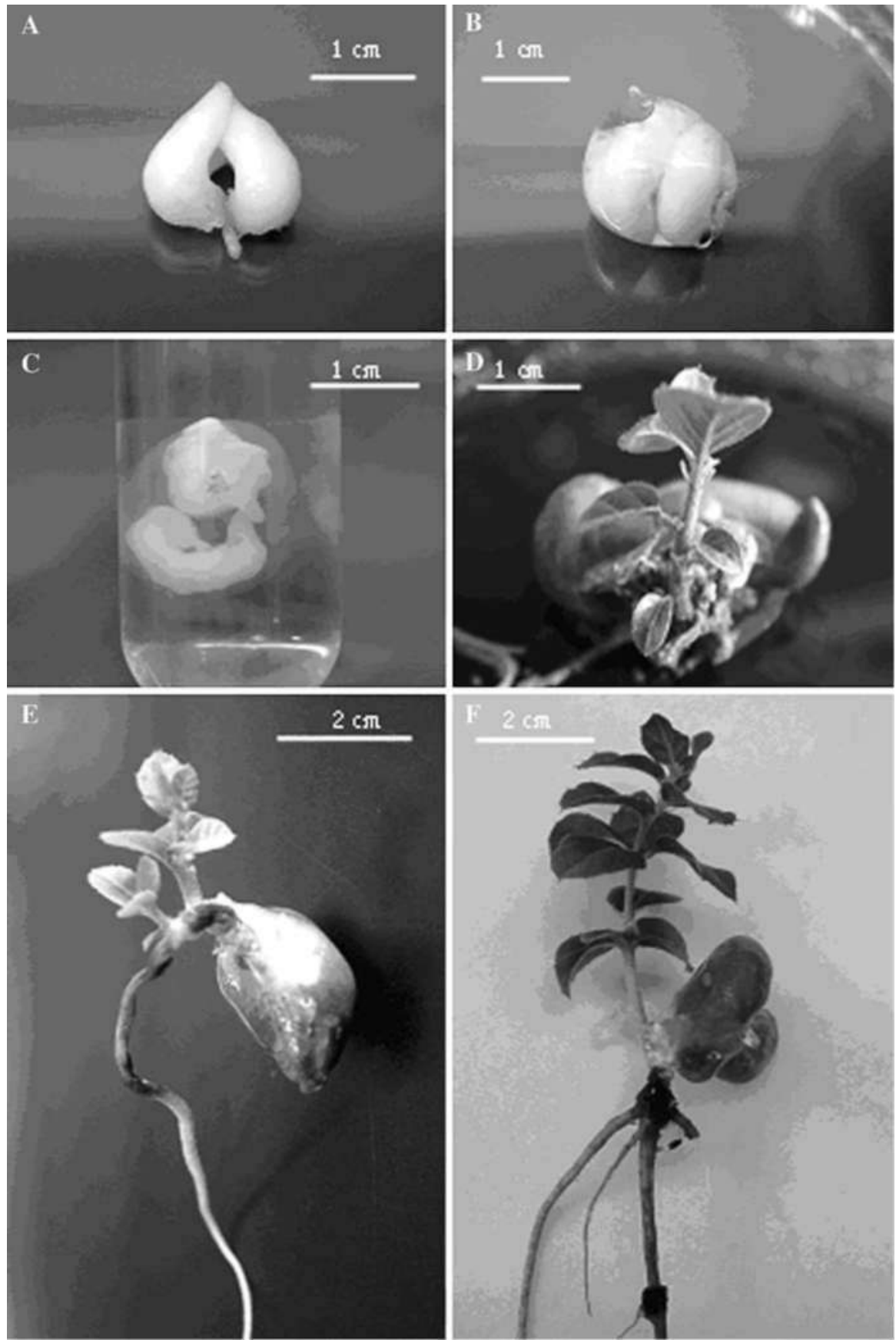

Experiment 1: effect of encapsulation combined with the mineral composition of the conversion medium on cork oak synthetic seed conversion

The log-linear analysis showed that both factors assayed, that is, both encapsulation of the somatic embryos and the presence of mineral nutrients in the conversion medium significantly affected conversion rate at the 0.05 level, but the interaction between both factors was not significant. The presence of mineral nutrients in the conversion substrate favoured conversion. The highest conversion rates were $67.5 \%$ for non-encapsulated embryos and $29.2 \%$ for encapsulated embryos set to convert on medium consisting of 
macronutrients (Sommer et al. 1975), microminerals and cofactors (Murashige and Skoog 1962), 1.5\% (w/v) sucrose, $1 \%(\mathrm{w} / \mathrm{v})$ agar, $0.2 \mathrm{uM} \mathrm{BA}$ and $0.5 \mathrm{uM} \mathrm{IB} \mathrm{A.}$ On the contrary, the conversion rate of non-encapsulated cork oak somatic embryos on medium without mineral nutrients or further additives dropped to $17 \%$, and to $0 \%$ in the case of encapsulated embryos.

\section{Experiment 2: effect of the addition of sucrose} and mineral nutrients to the capsule on cork oak synthetic seed conversion

Conversion of cork oak synthetic seeds was significantly higher with the addition of mineral nutrients to the capsule (16.3 and $9.5 \%$ conversion rates for embryos encapsulated with and without sucrose added to the capsule, respectively) than without the addition of mineral nutrients to the capsule (4.6 and $0 \%$ conversion rates for embryos encapsulated with and without sucrose added to the capsule, respectively). There were no significant differences due to the effect of sucrose or to the interaction between both factors.

Experiment 3: effect of the addition of sucrose to the capsule and cold storage of synthetic seeds on the conversion rate

A statistically significant difference was obtained between encapsulated somatic embryos converted on basal conversion medium without prior cold treatment (conversion rate $73 \%, P<0.05$ ) and all other treatments (Fig. 3). Neither the addition of sucrose to the capsule of cork oak synthetic seeds nor the interaction between the addition of sucrose to the capsule and cold storage of the encapsulated somatic embryos were statistically significant. Somatic embryos encapsulated with 3\% sucrose and cold stored at $4{ }^{\circ} \mathrm{C}$ for two months reached a $53 \%$ conversion rate (Fig. 3).

Experiment 4: effect of encapsulation, cold storage at $4^{\circ} \mathrm{C}$ and calcium chloride concentration on the conversion of encapsulated somatic embryos

Neither encapsulation nor later cold storage at $4{ }^{\circ} \mathrm{C}$ for two months of the cork oak somatic embryos significantly affected conversion rate as compared to the controls. No significant differences were found

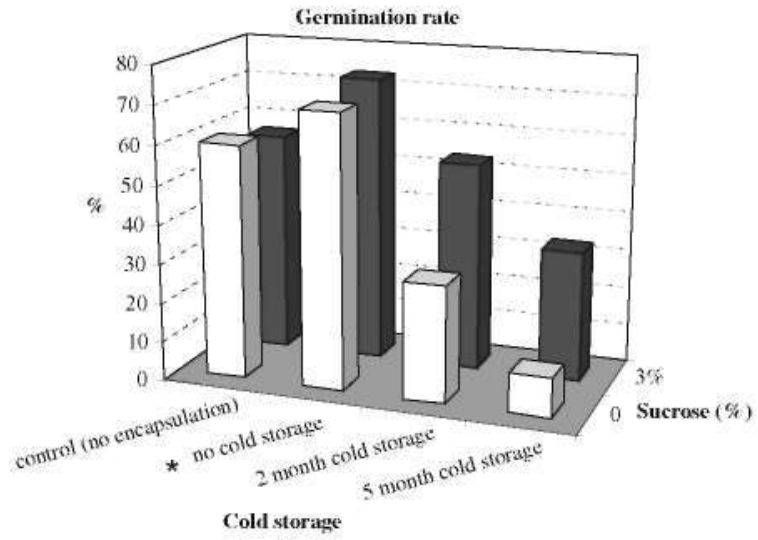

Fig. 3 Effect of the addition of sucrose to the capsule and cold storage of synthetic seeds on the conversion rate. Treatments marked with an asterisk are statistically significant at the 0.05 level

between alginate complexing with 50 or with $100 \mathrm{mM} \mathrm{CaCl} 2$ either. Conversion rates reached $65 \%$ for non-encapsulated embryos (controls), 40 and $70 \%$ for non-cold stored, encapsulated embryos with 50 or with $100 \mathrm{mM} \mathrm{CaCl} 2$ complexation, respectively, and 55 and $30 \%$ for cold-stored, encapsulated embryos with 50 or with $100 \mathrm{mM} \mathrm{CaCl} 2$ complexation, respectively.

\section{Discussion}

Mathematical models for the growth and conversion of somatic embryos have been developed with the aim of monitoring the large scale production of microplants from other economically important species, such as oil palm (Konan et al. 2006). The technique developed here for monitoring the growth of cork oak somatic embryos inside the Petri dish with a standard system of image capture and digital image analysis simplifies the problem of quantifying and comparing growth in different treatments and culture media. The method warrants aseptic conditions preventing eventual contamination risks and opens the possibility of an automated control of the cultures for the future up scaling of plant production.

The presence of mineral nutrients favoured the conversion rate of synthetic seeds in cork oak. This result provided a clue for the importance of mineral nutrients on the viability of encapsulated somatic embryos. The addition of mineral nutrients to the capsule 
confirmed that result. Also, previous stratification and the addition of sucrose proved to be beneficial for the conversion of cork oak synthetic seeds. Other researchers also have observed improved conversion results using the so-called synthetic endosperms (Germana et al. 2007). Also in the related species $Q$. robur, significant improvements in conversion rates $(26 \%)$ were found for one cell line of pedunculate oak somatic embryos with the inclusion of nutrients and sugar to the encapsulation matrix over the control group without nutrients in the capsule (Prewein and Wilhelm 2003). Other authors have observed similar results in other woody species (Maruyama et al. 1997). On the other hand, the encapsulation of narrow-leaved ash somatic embryos in sodium alginate beads adversely affected plant conversion, regardless of nutrient additions to the alginate, and $65 \%$ of non-encapsulated somatic embryos were successfully converted into whole plantlets on plant growth regulator-free MS medium in comparison to $23 \%$ of the encapsulated ones (Tonon et al. 2001). Some authors noted that variables related to the encapsulation method, including alginate type and concentration, medium and methods used to produce synthetic seeds, were responsible for significant variation in conversion percentages in alfalfa, carrot and celery (Redenbaugh et al. 1987, 1993). On the other hand, the concentration of $\mathrm{CaCl} 2$ was not relevant for the quality of synthetic seeds in our case.

It has been reported that both encapsulated and non-encapsulated somatic embryos of interior and black spruce survived one month of storage at $4^{\circ} \mathrm{C}$ with no loss in conversion capacity (Lulsdorf et al. 1993). Encapsulated somatic embryos of Pinus patula stored at 2 or $4^{\circ} \mathrm{C}$ for four months showed high conversion rates (73 to $61 \%$, resp.), but when stored at higher temperatures (e.g., room temperature $27^{\circ} \mathrm{C}$ ) for 40 days they showed only $6 \%$ conversion (Malabadi and van Staden 2005). The conversion percentage decreased with an increase in storage time and temperature. Nevertheless, storage of encapsulated somatic embryos at low temperature for longer periods resulted in a sudden drop in the conversion percentage to less than $6 \%$ on 130 and 140 days. Redenbaugh et al. (1987) proposed that a decline in the conversion frequency observed among encapsulated propagules stored at low temperatures may have resulted because of inhibited respiration of plant tissues, perhaps due to alginate cover. We observed a moderate decrease of conversion rate in our cork oak synthetic seeds stored at $4^{\circ} \mathrm{C}$ for two or five months, from $73 \%$ in the case of somatic embryos encapsulated with $3 \%$ sucrose, to $53 \%$ for embryos stored at $4^{\circ} \mathrm{C}$ for two months, and $33 \%$ for embryos stored at $4^{\circ} \mathrm{C}$ for five months. Successful conversion of encapsulated somatic embryos following the cold storage $\left(4^{\circ} \mathrm{C}\right)$ indicates that the method described in this paper could be potentially used to preserve desirable elite genotypes of cork oak over a short period. This could also facilitate transport of synthetic seeds to extension centres and laboratories of distant places while maintaining their viability. We conclude that the present study reports an efficient optimization of encapsulation parameters for the large scale production and in vitro storage of cork oak synthetic seeds from somatic embryos. These results are a step towards adapting storage techniques for synthetic seeds of this species.

Acknowledgements This work was supported both by the Joint Collaboration Program between the National Institute of Agricultural Research (INIA) and TRAGSA (CON 06-019), and by the RTA 2005-00118-C02-02 project of the Spanish Ministry of Education and Science (MEC). Pintos was recipient of a contract funded by TRAGSA in the frame of the CON 06-019 Joint Collaboration Program. We thank Elena Garcia (INIA), for the auxiliary work.

\section{References}

Bapat VA, Rao P (1988) Sandalwood plantlets from synthetic seeds. Plant Cell Rep 7:434^136. doi:10.1007/BF00272751

Bornman CH (1993) Maturation of somatic embryos. In: Redenbaugh K (ed) Synseeds: applications of synthetic seeds to crop improvement. CRC Press, Boca Raton, pp 105-114

Bueno MA, Astorga R, Manzanera JA (1992) Plant Regeneration through Somatic Embryogenesis in Quercus suber. Physiol Plant 85:30-34. doi: 10.1111/j. 1399-30541992. tb05259.x

Cangahuala-Inocente GC, Dal Vesco LL, Steinmacher D et al (2007) Improvements in somatic embryogenesis protocol in Feijoa (Acca sellowiana (Berg) Biuret): Induction, conversion and synthetic seeds. Sci Hortic 111:228-234. doi: 10.1016/j.scienta.2006.10.030

Chalupa V (1990) Plant regeneration by somatic embryogenesis from cultured immature embryos of oak (Quercus robur L.) and linden (Tilia cordata Mill.). Plant Cell Rep 9:398-401. doi:10.1007/BF00232408

Garcia-Martin G, Gonzalez-Benito ME, Manzanera JA (2001) Quercus suber L. somatic embryo germination and plant conversion: Pretreatments and germination conditions. In 
Vitro Cell Dev Biol Plant 37:190-198. doi:10.1007/ sl1627-001-0033-y

Garcia-Martin G, Manzanera JA, Gonzalez-Benito ME (2005) Effect of exogenous ABA on embryo maturation and quantification of endogenous levels of $\mathrm{ABA}$ and IAA in Quercus suber somatic embryos. Plant Cell Tissue Organ Cult 80:171-177. doi:10.1007/s11240-004-1056-y

Germana MA, Hafiz IA, Micheli M et al (2007) Preliminary research on conversion of encapsulated somatic embryos of Citrus reticulata Blanco, cv Mandarino Tardivo di Ciaculli. Plant Cell Tissue Organ Cult 88:117-120. doi: 10.1007/s11240-006-9185-0

Ghosh B, Sen S (1994) Plant regeneration from alginate encapsulated somatic embryos of Asparagus cooperi Baker. Plant Cell Rep 13:381-385

Gonzalez-Benito ME, Herradon E, Martin C (1999) The development of a protocol for the encapsulation-desiccation and in vitro culture of embryonic axes of Quercus suber $\mathrm{L}$ and $Q$. ilex L. Silvae Genet 48:25-28

Ipekci Z, Gozukirmizi N (2003) Direct somatic embryogenesis and synthetic seed production from Paulownia elongata. Plant Cell Rep 22:16-24. doi:10.1007/s00299-003-0650-5

Ishii K, Thakur R, Jain SM (1999) Somatic embryogenesis and evaluation of variability in somatic seedlings of Quercus serrata by RAPD markers. In: Jain SM, Gupta PK, Newton RJ (eds) Somatic embryogenesis in woody plants, vol 4. 4. Kluwer Academic Publishers, Dordrecht, pp $403^{\wedge} 14$

Konan EE, Durand-Gasselin T, Kouadio JY et al (2006) A modeling approach of the in vitro conversion of oil palm (Elaeis guineensis) somatic embryos. Plant Cell Tissue Organ Cult 84:99-112. doi:10.1007/s11240-005-9010-1

Lulsdorf MM, Tautoras TE, Kikcio SI et al (1993) Germination of encapsulated embryos of interior spruce (Picea glauca engelmannii complex) and black spruce (Picea mariana Mill.). Plant Cell Rep 12:385-389. doi:10.1007/BF00234697

Malabadi RB, van Staden J (2005) Storability and germination of sodium alginate encapsulated somatic embryos derived from the vegetative shoot apices of mature Pinus patula trees. Plant Cell Tissue Organ Cult 82:259-265. doi: 10.1007/s11240-005-1313-8

Manjkhola S, Dhar U, Joshi M (2005) Organogenesis, embryogenesis, and synthetic seed production in Arnebia euchroma - a crititcally endangered medicinal plant of the Himalaya. In Vitro Cell Dev Biol Plant 41:244-248. doi: 10.1079/IVP2004612

Manzanera JA, Astorga R, Bueno MA (1993) Somatic Embryo Induction and Germination in Quercus suber L. Silvae Genet 42:90-93

Maruyama E, Kinoshita I, Ishii K et al (1997) Alginateencapsulated technology for the propagation of the tropical forest trees: Cedrela odorata L., Guazuma crinita MART., and Jacaranda mimosaefolia D. DON. Silvae Genet 46:17-23

Maruyama E, Hosoi Y, Ishii K (2003) Somatic embryo culture for propagation, artificial seed production, and conservation of sawara cypress (Chamaecyparis pisifera Sieb. et Zucc). J For Res 8:1-8. doi:10.1007/s103100300000
Mauri PV, Manzanera J A (2003) Induction, maturation and germination of holm oak (Quercus ilex L.) somatic embryos. Plant Cell Tissue Organ Cult 74:229-235. doi: 10.1023/A: 1024072913021

Mauri PV, Manzanera JA (2004) Effect of abscisic acid and stratification on somatic embryo maturation and germination of holm oak (Quercus ilex L.). In Vitro Cell Dev Biol Plant 40:495^98. doi:10.1079/IVP2004557

Muralidharan EM, Mascarenhas AF (1995) Somatic embryogenesis in Eucalyptus. In: Jain S, Gupta P, Newton R (eds) Somatic embryogenesis in woody plants, vol 2. Kluwer, Dordrecht, pp $23^{\wedge} 0$

Murashige T, SkoogF (1962) A revised medium for rapid growth and bioassays with tobacco tissue cultures. Physiol Plant 15:473^97. doi:10.1111/j.1399-3054.1962.tb08052.x

Naik SK, Chand PK (2006) Nutrient-alginate encapsulation of in vitro nodal segments of pomegranate (Punica granatum L.) for germplasm distribution and exchange. Sci Hortic 108:247-252. doi:10.1016/j.scienta.2006.01.030

Nieves N, Lorenzo JC, Blanco M et al (1995) Artificial endosperm assays for embryos of Cleopatra mandarin (Citrus reshni Hort ex Tan). Turrialba 45:64-69

Prewein C, Wilhelm E (2003) Plant regeneration from encapsulated somatic embryos of pedunculate oak (Quercus robur L.). In Vitro Cell Dev Biol Plant 39:613-617. doi: 10.1079/IVP2003453

Redenbaugh K, Fuji JO, Slade D (1993) Hydrated coatings for synthetic seed. In: Redenbaugh K (ed) Synseed-applications of synthetic seeds to crop improvement. CRC Press, Boca Raton, Florida, pp 183-202

Redenbaugh K, Slade D, Viss PR et al (1987) Encapsulation of somatic embryos in synthetic seed coats. Hortic Sci 22:803-809

Singh B, Sharma S, Rani G (2007) In vitro response of encapsulated and non-encapsulated somatic embryos of Kinnow mandarin (Citrus nobilis Lour x C. deliciosa Tenora). Plant Biotechnol Rep 1:101-107. doi:10.1007/ si 1816-007-0015-6

Sommer H, Brown C, Kormanik P (1975) Differentiation of plantlets in longleaf pine (Pinus palustris Mill.) tissue cultured in vitro. Bot Gaz 136:196-200. doi: 10.1086/336802

Tonon G, Capuana M, Rossi C (2001) Somatic embryogenesis and embryo encapsulation in Fraxinus angustifolia Vhal. J Hortic Sci Biotechnol 76:753-757

Utomo HS, Wenefrida I, Meche MM et al (2008) Synthetic seed as a potential direct delivery system of mass produced somatic embryos in the coastal marsh plant smooth cordgrass (Spartina alterniflora). Plant Cell Tissue Organ Cult 92:281-291. doi: 10.1007/s1 1240-007-9334-0

Wang Q, Munir M, Nachman S et al (2004) Cryopreservation of grapevine (Vitis spp.) embryogenic cell suspensions by encapsulation-vitrification. Plant Cell Tissue Organ Cult 77:265-275

Wilhelm E, Endemann M, Hristoforoglu K, et al (1999) Somatic embryogenesis in oak (Quercus robur L.) and production of artificial seeds. In: Espinel S, Ritter E (ed) Proceedings of the application of biotechnology to forest genetics, Biofor 99, Vitoria (Spain), pp 213-225 